\title{
Rancang Bangun Sistem Pendeteksian Penyakit Tanaman Anthurium Dengan Metode Variable-Centered Intellegent Rule System (VCIRS)
}

\author{
Ade Candra Saputra $^{1)}$, Jadiaman Parhusip ${ }^{2)}$, Yusup Hidayat ${ }^{3)}$ \\ 122)3) Teknik Informatika, Teknik, Universitas Palangka Raya \\ Kampus UPR Tunjung Nyaho Jalan Yos Sudarso, Palangka Raya \\ 1) ade.chandra.saputra.tumbai@gmail.com \\ ${ }^{2)}$ parhusip.jadiaman@gmail.com \\ 3) yusufxyz114@gmail.com
}

\begin{abstract}
Abstrak
Sistem pendeteksian penyakit tanaman anthurium yang telah diaplikasikan ini adalah suatu sistem yang dapat membantu mendiagnosa penyakit pada tanaman anthurium berdasarkan gejala yang diketahui pengguna dan memberikan solusi atas masalah tersebut. Sistem ini dimaksudkan untuk memberikan kemudahan akses informasi mengenai jenis penyakit anthurium dan solusi pengobatannya kepada para pekebun, penggemar anthurium, atau bahkan orang awam yang memang membutuhkan informasi tersebut.

Sistem ini menggunakan data penyakit dan pengobatan yang bersumber dari pakar tanaman anthurium. Terdapat 13 penyakit dan 44 gejala penyakit yang menjadi data pengetahuan sistem. Metodologi penelitian yang dilakukan meliputi proses akuisisi pengetahuan, representasi pengetahuan, perancangan VCIRS, analisis dan perancangan sistem, implementasi dan pengujian sistem.

Dalam penelitian ini dilakukan uji coba sistem pendeteksian tanaman anthurium dilakukan sebanyak 13 kali. Hasil uji coba menunjukkan bahwa sistem sudah bisa mendiagnosa penyakit tanaman anthurium dengan tingkat akurasi sebesar 92,3\%. Kesalahan terjadi karena diagnosa terhadap gejala yang dipakai dibeberapa penyakit dan ternyata memiliki nilai usage rate yang lebih tinggi di suatu rule VCIRS.
\end{abstract}

Kata kunci: Sistem Pendeteksian, Anthurium, VCIRS

\begin{abstract}
The anthurium plant disease detection system that has been built is a system that can help diagnose diseases in anthurium plants based on symptoms input by the user and provide solutions to these problems. This system is intended to provide easy access to information about the types of anthurium diseases and their treatment solutions for planters, anthurium enthusiasts, or nonexpert who really need this information.

This system uses disease and treatment data sourced from anthurium plant experts. There are 13 diseases and 44 symptoms of disease which becomes the system knowledge base. The research methodology carried out includes the process of knowledge acquisition, knowledge representation, VCIRS design, system analysis and design, system implementation and testing.

In this study, the anthurium plant detection system was tested 13 times. The trial results showed that the system was able to diagnose anthurium plant diseases with an accuracy rate of 92.3\%. Errors occur because of the diagnosis of symptoms used in several diseases and it turns out to have a higher usage rate value in a VCIRS rule.
\end{abstract}

Keywords: Detection System, Anthurium, VCIRS 


\section{PENDAHULUAN}

Sistem pakar memiliki kemampuan meniru keahlian seorang pakar dalam bidang tertentu karena di dalamnya terdapat basis pengetahuan yang diperoleh dari seorang pakar. Sistem pakar digunakan untuk memecahkan dan mencari solusi akhir suatu masalah berdasarkan data dan fakta yang ada.

Tanaman anthurium atau yang dahulu dikenal dengan nama gelombang cinta merupakan salah satu tanaman hias paling dikenal. Salah satu penyebab turunnya peminatan tanaman hias ini ialah para penggemar dan pekebun anthurium sebagian besar tidak mengetahui jenis dan penyebab penyakit yang diderita oleh tanaman tersebut. Hanya orang tertentu saja yang dapat melakukan konsultasi dengan seorang pakar, dan paham akan apa yang dimaksud oleh pakar tersebut. Tidak jarang seorang penggemar anthurium rela mengeluarkan uang untuk merawat dan memelihara tanaman yang begitu populer dan mahal saat itu tersebut. Sehingga sekarang harganya berkisar di sepuluhribu hingga ratusan ribu saja.

Menurut [1] masalah serangan hama dan penyakit tanaman merupakan penghambat utama dalam meningkatkan produktivitas pertanian. Diagnosa penyakit pada tanaman biasanya dilakukan oleh seorang peneliti tanaman berdasarkan gejala yang diderita. Kesimpulan penyakit ini bisa didapat dari gejala penyakit yang timbul.

Variable Centered Intelligent Rule System (VCIRS) merupakan gabungan dari RBS dan RDR. Penelitian yang dilakukan [2] dengan studi kasus mendiagnosa penyakit anjing melakukan penelitian menggunakan metode VCIRS. Prototipe pakar menggunakan metode ini mampu membangun basis pengetahuan, memperbarui pengetahuan dan proses inferensi. Arsitektur sistem diadaptasi dari $R B S$ dan ia mengambil keuntungan-keuntungan yang ada dari $R D R$. Sistem ini mengorganisasi $R B$ dalam struktur tertentu sehingga pembangunan pengetahuan, inferensia pengetahuan yang berdayaguna dan peningkatan evolusional dari kinerja sistem dapat diperoleh pada waktu yang sama. Oleh karena itu, peneliti tertarik untuk membangun sistem pendeteksian dengan metode VCIRS untuk mendiagnosis penyakit pada tanaman anthurium.

\subsection{Rumusan Masalah}

Rumusan masalah yang akan dibahas adalah "bagaimana merancang dan membangun sistem pakar untuk mendeteksi penyakit tanaman anthurium dengan memanfaatkan metode VCIRS?"

\subsection{Batasan Masalah}

Adapun batasan masalah dalam penelitian ini adalah :

1. Jenis penyakit yang dapat diidentifikasi oleh program ini dibatasi untuk semua jenis penyakit pada tanaman anthurium.

2. Bentuk penyajian basis pengetahuan yang digunakan dalam sistem adalah metode VCIRS.

3. Skenario pengujian dilakukan terhadap tanaman anthurium sebanyak 13 pengujian.

\subsection{Tujuan Penelitian}

Tujuan penelitian ini adalah sebagai berikut :

1. Merancang dan membuat aplikasi sistem pakar untuk memberikan informasi mengenai jenisjenis penyakit pada tanaman Anthurium dan cara penanggulangannya.

2. Memanfaatkan metode VCIRS dalam menyelesaikan kasus mendeteksi penyakit tanaman anthurium.

\section{TINJAUAN PUSTAKA}

\subsection{Sistem Pakar}

Sistem pakar merupakan sistem yang berbasis pengetahuan, maka sistem pakar memiliki salah satu komponen bernama basis pengetahuan (knowledge base) yang di dapat dari pengetahuan para ahli untuk memecahkan masalah. Jadi, pada dasarnya sistem pakar terdiri dari 3 komponen utama menurut [3], yaitu basis pengetahuan, mesin inferensia, dan antarmuka pengguna. 


\subsection{VCIRS}

Sistem ini mengorganisasi $R B$ dalam struktur spesial sehingga pembangunan pengetahuan, inferensia pengetahuan yang berdayaguna dan peningkatan evolusional dari kinerja sistem dapat didapatkan pada waktu yang sama. Istilah "Intelligent" dalam VCIRS menekankan pada keadaan sistem ini yang dapat "belajar" untuk meningkatkan kinerja sistem dari pengguna sistem selama pembangunan pengetahuan (melalui analisis nilai) dan penghalusan pengetahuan (dengan pembangkitan rule) [4].

Proses analisis nilai, yang disebut dengan usage assignment (pemberian nilai kegunaan), adalah untuk menentukan derajat kegunaan dari rule/node/variabel dalam KB. Usage assignment menggunakan informasi yang disimpan dalam Variable-Centered Rule Structure. Persamaan (1) menghitung Variable Usage Rate untuk variabel ke-i, (4) menghasilkan Node Usage Rate untuk node ke-j, sedangkan (3) mendefinisikan Rule Usage Rate untuk rule ke-k.

$$
\begin{aligned}
& V U R_{i}=\text { Credit }_{i} \times \text { Weight }_{i} \\
& \text { Weight }_{i}=N S_{i} \times C D_{i} \\
& C D_{i}=\frac{V O_{i}}{T V} \\
& N U R_{j}=\frac{\sum_{1}^{N} V U R_{i j}}{N} \\
& R U R_{k}=\frac{\sum_{1}^{N} N U R_{j k}}{N}
\end{aligned}
$$

Keterangan:

Credit $=$ kejadian dari variabel $i$ dalam Node Structure

Weight $=$ bobot $($ weight $)$ dari variabel ke node yang memilikinya

$N S=$ jumlah node yang berbagi (sharing) variabel $i$

$C D=$ derajat kedekatan sebuah variabel pada sebuah node

$V O=$ urutan dari variabel $i$ dalam suatu node

$T V=$ total variabel yang dimiliki oleh suatu node

\subsection{Certainty Factor}

Menurut [5] awal mula teori certainty factor (CF) diusulkan oleh Shortlife dan Buchanan pada 1975 untuk mengakomodasi ketidakpastian pemikiran seorang pakar. Seorang pakar/ahli dalam hal ini biasanya dokter sering kali menganalisis informasi yang ada dengan ungkapan seperti "mungkin", "kemungkinan besar", "hampir pasti". Untuk mengakomodasi hal ini kita menggunakan certainty factor guna menggambarkan tingkat keyakinan pakar terhadap masalah yang sedang dihadapi.

Salah satu cara untuk mendapatkan nilai kombinasi dua buah rule dengan evidence berbeda (E1 dan E2), tetapi hipotesis sama, yaitu:

If $E_{i}$ then $H$ Rule

$$
C F\left(H, E_{i}\right)=C F_{i}=C\left(E_{i}\right) \times C F\left(\text { Rule }_{i}\right)
$$

If $E_{j}$ then $H$ Rule

$$
\begin{aligned}
& C F\left(H, E_{j}\right)=C F_{j}=C\left(E_{j}\right) \times C F\left(\text { Rule }_{j}\right) \\
& C F\left(C F_{i} C F_{j}\right) \begin{cases}C F_{i}+C F_{j}\left(1-C F_{i}\right) & \text { jika } C F_{i}>0 \text { dan } C F_{j}>0 \\
\frac{C F_{i}+C F_{j}}{1-\left(\min \left\|C F_{i}|,| C F_{j}\right\|\right)} & \text { jika } C F_{i}<0 \text { atau } C F_{j}<0 \\
C F_{i}+C F_{j}\left(1+C F_{i}\right) & \text { jika } C F_{i}<0 \text { dan } C F_{j}<0\end{cases}
\end{aligned}
$$


Keterangan:

$E=$ fakta - fakta (evidence) yang ada

$H=$ hipotesis atau konklusi yang dihasilkan

$C F=$ tingkat keyakinan terjadinya hipotesis $H$ akibat adanya fakta-fakta

\subsection{Anthurium}

Genus anthurium berasal dari benua Amerika yang beriklim tropis. Tanaman ini memiliki seludang bunga, warna dan bentuk daun yang menarik sehingga saat ini banyak diminati masyarakat khususnya di Indonesia. Sifatnya yang memerlukan naungan atau tempat teduh dengan sinar matahari 30-60\%, Anthurium lebih sesuai dijadikan tanaman hias indoor [6].

\section{METODE PENELITIAN}

\subsection{Representasi Pengetahuan}

Tujuan representasi adalah untuk mengembangkan suatu struktur yang akan membantu pengkodean pengetahuan ke dalam program. Langkah yang dilakukan untuk membuat representasi pengetahuan aturan produksi adalah sebagai berikut [7]:

1. Pembuatan tabel keputusan (decision table)

Tabel keputusan merupakan suatu metode untuk mendokumentasikan pengetahuan. Tabel keputusan merupakan matrik kondisi yang dipertimbangkan dalam pendeskripsian aturan. Dalam studi kasus ini, tabel keputusan berisi hubungan antara gejala dan penyakit.

Tabel 1. Tabel keputusan (data diolah)

\begin{tabular}{|c|c|c|c|c|c|c|c|c|c|c|c|c|c|}
\hline Penyakit & $\begin{array}{l}\text { B } \\
\text { D }\end{array}$ & $\begin{array}{l}\mathrm{B} \\
\mathrm{K}\end{array}$ & $\begin{array}{l}\text { B } \\
\text { A }\end{array}$ & $\begin{array}{l}\text { B } \\
\text { B }\end{array}$ & $\begin{array}{l}\mathrm{L} \\
\mathrm{B}\end{array}$ & $\begin{array}{l}\mathrm{L} \\
\mathrm{F}\end{array}$ & $\begin{array}{l}\mathrm{K} \\
\mathrm{D}\end{array}$ & $\begin{array}{l}\mathrm{T} \\
\mathrm{H} \\
\mathrm{R} \\
\end{array}$ & $\begin{array}{l}\mathrm{A} \\
\mathrm{N} \\
\mathrm{T}\end{array}$ & $\begin{array}{l}\mathrm{S} \\
\mathrm{P} \\
\mathrm{T}\end{array}$ & $\begin{array}{l}\mathrm{U} \\
\mathrm{D}\end{array}$ & $\begin{array}{l}\mathrm{D} \\
\mathrm{K}\end{array}$ & $\begin{array}{l}\mathrm{D} \\
\mathrm{T}\end{array}$ \\
\hline $\begin{array}{l}\text { 1. Terdapat bercak-bercak berwarna } \\
\text { coklat }\end{array}$ & $\sqrt{ }$ & $\sqrt{ }$ & $\sqrt{ }$ & & & & & & & & & & \\
\hline $\begin{array}{l}\text { 2. Terdapat bercak-bercak berwarna } \\
\text { kehitaman }\end{array}$ & $\sqrt{ }$ & $\sqrt{ }$ & $\sqrt{ }$ & & & & & & & & & & \\
\hline 3. $\quad$ Daun busuk & $\sqrt{ }$ & $\sqrt{ }$ & $\sqrt{ }$ & $\sqrt{ }$ & & & & & & & & & \\
\hline $\begin{array}{l}\text { 4. Muncul noktah kecil berwarna } \\
\text { kuning pada daun }\end{array}$ & & $\sqrt{ }$ & $\sqrt{ }$ & & & & & & & & & & \\
\hline $\begin{array}{ll}5 . & \text { Seluruh permukaan daun berwarna } \\
\text { kuning }\end{array}$ & & $\sqrt{ }$ & $\sqrt{ }$ & & & & & & & & & & \\
\hline 6. $\quad$ Media terlalu lembap & & $\sqrt{ }$ & $\sqrt{ }$ & & & & & & & & & & \\
\hline 7. Aliran udara di lokasi tidak lancar & & $\sqrt{ }$ & $\sqrt{ }$ & & & & & & & & & & \\
\hline $\begin{array}{ll}8 . & \text { Pemberian pupuk kandang yang } \\
\text { berlebihan }\end{array}$ & & $\sqrt{ }$ & $\sqrt{ }$ & & & & & & & & & & \\
\hline 9. $\quad$ Komposisi media salah & & $\sqrt{ }$ & $\sqrt{ }$ & & & & & & & & & & \\
\hline 10. $\quad$ Akar busuk & & $\sqrt{ }$ & & & & & & & & & & & \\
\hline 11. Daun mengeluarkan bau tak sedap & & & $\sqrt{ }$ & & $\sqrt{ }$ & & & & & & & & \\
\hline 12. Tanaman layu seperti mati & & & $\sqrt{ }$ & & & & & & & & & & \\
\hline 13. Akar mudah putus & & & $\sqrt{ }$ & & & & & & & & & & \\
\hline $\begin{array}{l}\text { 14. Ujung daun terlihat menggulung } \\
\text { kekuningan seperti terbakar }\end{array}$ & & & $\sqrt{ }$ & & & & & & & & & & \\
\hline 15. Tanaman terlihat stress & & & $\sqrt{ }$ & & & & & & & & & & \\
\hline 16. Drainase buruk & & & $\sqrt{ }$ & & & & & & & & & & \\
\hline $\begin{array}{l}\text { 17. Kondisi lingkungan tumbuh tidak } \\
\text { baik }\end{array}$ & & & $\sqrt{1}$ & & & & & & & & & & \\
\hline $\begin{array}{ll}18 . & \text { Terdapat konodium cendawan } \\
\text { (jamur) }\end{array}$ & & & & $\sqrt{ }$ & & & & & & & & & \\
\hline 19. Melunakannya daun & & & & & $\sqrt{ }$ & & & & & & & & \\
\hline 20. Daun coklat & & & & & & $\sqrt{ }$ & & & & & & & \\
\hline 21. Tangkai Busuk & & & & & & $\sqrt{ }$ & & & & & & & \\
\hline 22. Memucat Tulang Daun & & & & & & $\sqrt{ }$ & & & & & & & \\
\hline $\begin{array}{l}\text { 23. Tulang daun berubah menjadi } \\
\text { coklat keabu-abuan }\end{array}$ & & & & & & $\sqrt{ }$ & & & & & & & \\
\hline 24. Menunduknya tangkai busuk & & & & & & $\sqrt{ }$ & & & & & & & \\
\hline 25. Berkas pembuluh darah basah & & & & & & $\sqrt{ }$ & & & & & & & \\
\hline 26. Media masam & & & & & & $\sqrt{ }$ & & & & & & & \\
\hline 27. Pucuk daun bunga jadi keriting & & & & & & & $\sqrt{ }$ & & & & & & \\
\hline
\end{tabular}


Tabel 1. Lanjutan

\begin{tabular}{|c|c|c|c|c|c|c|c|c|c|c|c|c|c|}
\hline Penyakit & $\begin{array}{l}\text { B } \\
\text { D }\end{array}$ & $\begin{array}{l}\mathrm{B} \\
\mathrm{K}\end{array}$ & $\begin{array}{l}\text { B } \\
\text { A }\end{array}$ & $\begin{array}{l}\mathrm{B} \\
\mathrm{B}\end{array}$ & $\begin{array}{l}\mathrm{L} \\
\mathrm{B}\end{array}$ & $\begin{array}{l}\mathrm{L} \\
\mathrm{F}\end{array}$ & $\begin{array}{l}\mathrm{K} \\
\mathrm{D}\end{array}$ & $\begin{array}{l}\mathrm{T} \\
\mathrm{H} \\
\mathrm{R}\end{array}$ & $\begin{array}{l}\text { A } \\
N \\
\text { T }\end{array}$ & $\begin{array}{l}\mathrm{S} \\
\mathrm{P} \\
\mathrm{T}\end{array}$ & $\begin{array}{l}\mathrm{U} \\
\mathrm{D}\end{array}$ & $\begin{array}{l}\mathrm{D} \\
\mathrm{K}\end{array}$ & $\begin{array}{l}\mathrm{D} \\
\mathrm{T}\end{array}$ \\
\hline 28. Mahkota bunga jadi keriting & & & & & & & $\sqrt{ }$ & & & & & & \\
\hline $\begin{array}{l}\text { 29. Terdapat sebuk putih yang } \\
\text { menempel di bawah daun (kutu) }\end{array}$ & & & & & & & $\sqrt{ }$ & & & & & & \\
\hline $\begin{array}{ll}30 . & \text { Terdapat banyak semut }\end{array}$ & & & & & & & $\sqrt{ }$ & & & & & & \\
\hline $\begin{array}{l}\text { 31. Permukaan daun berwarna } \\
\text { keperakan }\end{array}$ & & & & & & & & $\sqrt{ }$ & $\sqrt{ }$ & & & & \\
\hline 32. Daun melintir/keriting & & & & & & & & $\sqrt{ }$ & & & & & \\
\hline 33. Seludang bunga bercak coklat & & & & & & & & & $\sqrt{ }$ & & & & \\
\hline 34. Seludang tampak berair & & & & & & & & & $\sqrt{ }$ & & & & \\
\hline $\begin{array}{ll}35 . & \text { Daun dipenuhi lubang- } \\
\text { lubang/lendir }\end{array}$ & & & & & & & & & & $\sqrt{ }$ & & & \\
\hline 36. Daun dipenuhi lubang & & & & & & & & & & & $\sqrt{ }$ & & \\
\hline $\begin{array}{l}\text { 37. Terdapat telur kupu-kupu di balik } \\
\text { daun }\end{array}$ & & & & & & & & & & & $\sqrt{ }$ & & \\
\hline $\begin{array}{ll}38 . & \text { Permukaan daun terasa } \\
& \text { bergelombang jika diraba }\end{array}$ & & & & & & & & & & & & $\sqrt{ }$ & \\
\hline 39. Warna daun pudar (gradasi) & & & & & & & & & & & & $\sqrt{ }$ & \\
\hline 40. Daun mengeriput & & & & & & & & & & & & $\sqrt{ }$ & \\
\hline 41. Warna semakin hijau muda & & & & & & & & & & & & $\sqrt{ }$ & \\
\hline $\begin{array}{l}\text { 42. Daun terbakar tampak cokelat } \\
\text { mengering }\end{array}$ & & & & & & & & & & & & & $\sqrt{ }$ \\
\hline 43. Bila daun diremas mudah hancur & & & & & & & & & & & & & $\sqrt{ }$ \\
\hline $\begin{array}{l}\text { 44. Sebagian daun terbakar disertai } \\
\text { kekuningan }\end{array}$ & & & & & & & & & & & & & $\sqrt{ }$ \\
\hline
\end{tabular}

2. Pengkonversian tabel keputusan menjadi aturan produksi

Representasi pengetahuan yang berbentuk aturan produksi dibentuk dari pengubahan keputusan. Pembuatan suatu aturan dilakukan dengan beberapa tahapan.

\subsection{Perancangan KB VCIRS}

Setelah memperoleh pengetahuan mengenai tanaman anthurium dari sumber-sumber diatas, selanjutnya pengetahuan tersebut akan dikumpulkan dalam suatu sistem database dan dikelompokkan sesuai gejala dan ciri-ciri tanaman anthurium ditambah dengan informasi lain yang mendukung dalam pembuatan basis pengetahuan. Representasi yang digunakan adalah representasi dalam bentuk rule base. Bentuk rule base ini akan disimpan pada knowledge base yang sebelumnya rule base ini diubah dahulu ke dalam bentuk VCIRS sehingga dapat disimpan menjadi knowledge base.

\subsection{Perancangan Mesin Inferensia}

Pada proses inferensi pada sistem digunakan metode forward chaining dan untuk menentukkan nilai/tingkat kepercayaan setiap kemungkinan digunakan certainty factor. Dalam sistem yang akan dibangun terdapat dua jenis faktor kepastian yaitu faktor kepastian dari user terhadap suatu gejala tertentu dan nilai faktor kepastian dari pakar. Faktor kepastian $(\mathrm{CF}[\mathrm{H}, \mathrm{E}])$ merupakan penggabungan antra $\mathrm{CF}$ user $[\mathrm{E}]$ dan $\mathrm{CF}$ pakar $[\mathrm{H}]$. Selanjutnya, dicari nilai CFR dengan mengkalikan hasil $\mathrm{CF}[\mathrm{H}, \mathrm{E}]$ dengan nilai $R U R$ suatu rule hasil diagnosa tersebut [8]. 
Tabel 2. Faktor keyakinan user terhadap suatu gejala [8]

\begin{tabular}{|c|l|c|}
\hline No. & \multicolumn{1}{|c|}{ Keterangan } & Nilai User \\
\hline 1. & Tidak & $0.1(10 \%)$ \\
\hline 2. & Tidak Tahu & $0.2(20 \%)$ \\
\hline 3. & Kurang Tahu & $0.4(40 \%)$ \\
\hline 4. & Cukup Yakin & $0.6(60 \%)$ \\
\hline 5. & Yakin & $0.8(80 \%)$ \\
\hline 6. & Sangat Yakin & $1.0(100 \%)$ \\
\hline
\end{tabular}

\subsection{Analisis dan Perancangan Sistem}

Desain sistem dibuat berdasarkan analisis kebutuhan yang telah direncanakan pada analisis sistem di atas. Adapun cara yang digunakan untuk membuat desain adalah dengan menggunakan model objek Data Flow Diagram (DFD). Adapun desain sistem yang akan dibuat antara lain DFD (Data Flow Diagram) dan ERD (Entity Relationship Diagram).

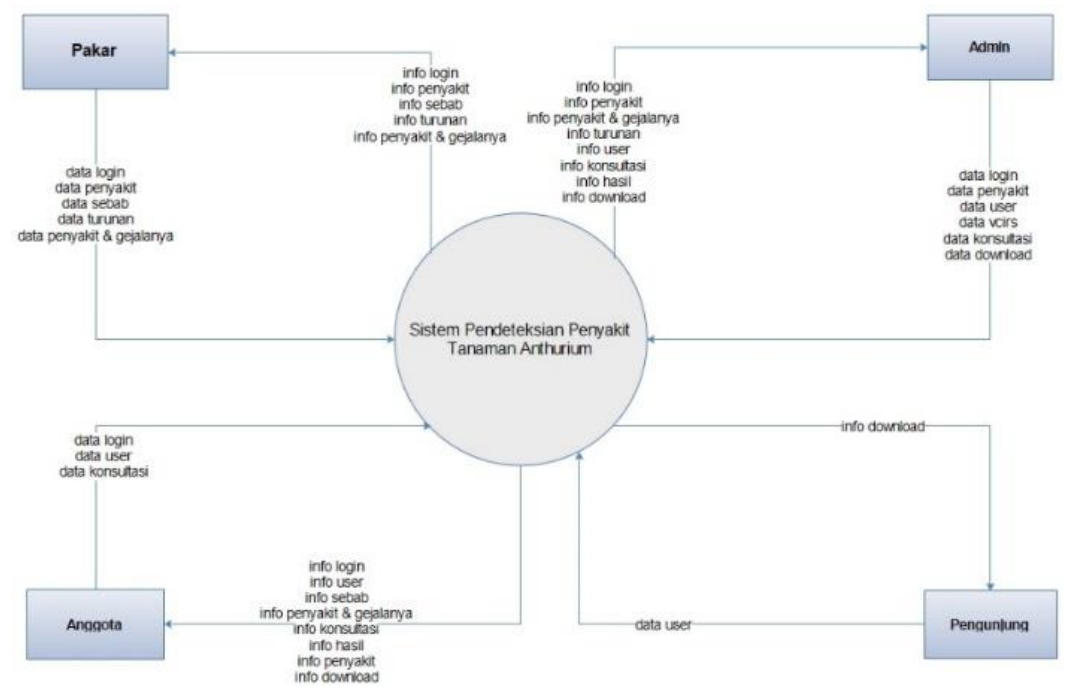

Gambar 1. Diagram konteks sistem

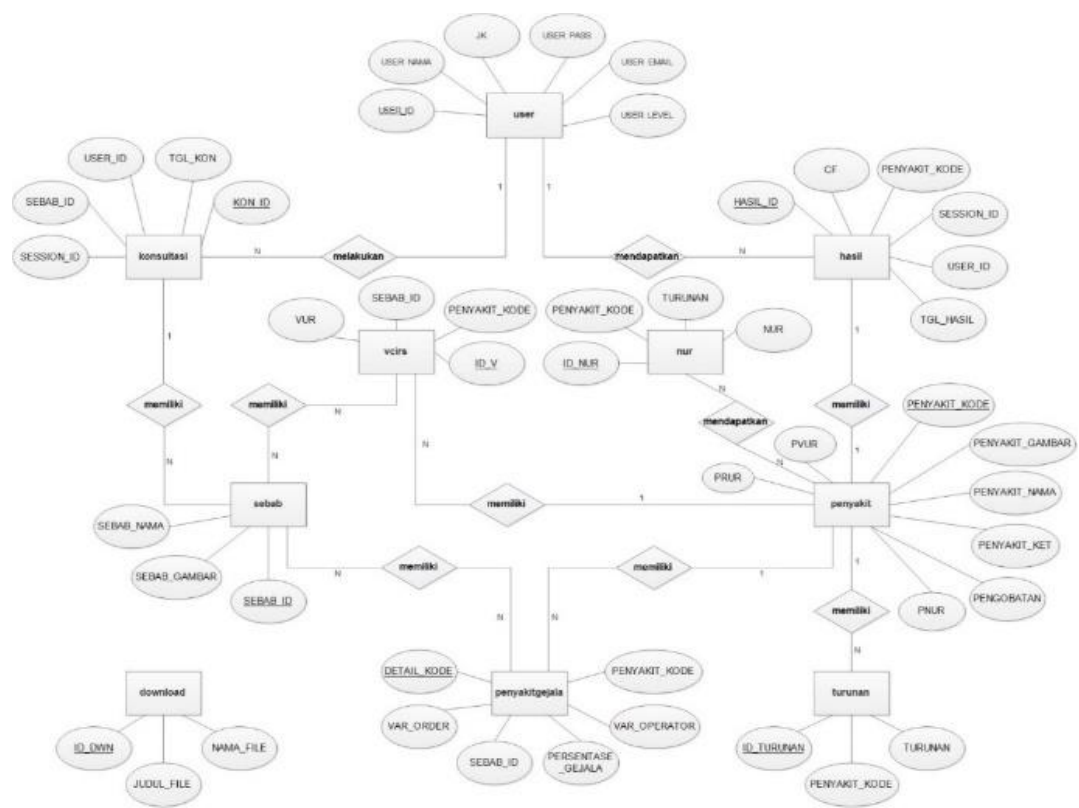

Gambar 2. ERD system 


\subsection{Pengujian}

Pengujian dilakukan dengan cara membandingkan hasil dari diagnosa sistem dengan hasil diagnosa pakar. Penilaian mengunakan presentase dari $1-100 \%$. Nilai akurasi didapat dari hasil diagnosis dari sistem pakar dibandingkan dengan hasil diagnosis pakar tanaman anthurium. Rumusnya sebagai berikut:

Nilai_akurasi $=\frac{\text { Jumlah_pengujian_true }}{\text { Jumlah_seluruh_pengujian }} \times 100 \%$

\section{PEMBAHASAN}

Tabel 2. Hasil uji coba penelitian

\begin{tabular}{|c|l|l|c|c|}
\hline $\begin{array}{c}\text { Pengujian } \\
\text { Ke- }\end{array}$ & \multicolumn{1}{|c|}{ Diagnosa Pakar } & Diagnosa Sistem & $\begin{array}{c}\text { Persentase CF } \\
\text { Sistem }\end{array}$ & Hasil \\
\hline 1. & Siput & Siput & $37 \%$ & True \\
\hline 2. & Bercak Daun & Busuk Akar & $64 \%$ & False \\
\hline 3. & Busuk Akar & Busuk Akar & $23 \%$ & True \\
\hline 4. & Busuk Akar & Busuk Akar & $55 \%$ & True \\
\hline 5. & Kutu Daun & Kutu Daun & $56 \%$ & True \\
\hline 6. & Thrips $s p$ & Thrips sp & $52 \%$ & True \\
\hline 7. & Bonggol Busuk & Bonggol Busuk & $68 \%$ & True \\
\hline 8. & Layu Bakteri & Layu Bakteri & $57 \%$ & True \\
\hline 9. & Anranoksa & Anranoksa & $46 \%$ & True \\
\hline 10. & Layu Fusairum & Layu Fusairum & $29 \%$ & True \\
\hline 11. & Ulat Daun & Ulat Daun & $50 \%$ & True \\
\hline 12. & Daun Keriting & Daun Keriting & $23 \%$ & True \\
\hline 13. & Daun Terbakar & Daun Terbakar & $41 \%$ & True \\
\hline Akurasi Pengujian = (Hasil True Pengujian/Total Pengujian)*100\% & \\
\hline \multicolumn{7}{|l}{$=(12 / 13))^{*} 100 \%$} \\
\hline
\end{tabular}

Tabel diatas menunjukan hasil uji coba penelitian dengan akurasi pengujian ialah 92,3\%. Kemungkinan kesalahan terjadi karena diagnosa terhadap gejala yang dipakai dibeberapa penyakit dan ternyata memiliki nilai usage rate yang lebih tinggi di suatu rule VCIRS. Sedangkan gejala tersebut lebih tepat disimpulkan terhadap penyakit yang usage rate nya lebih rendah namun hanya memiliki semua gejala tersebut.

\section{KESIMPULAN}

Setelah menyelesaikan perancangan sistem pendeteksian penyakit tanaman anthurium dengan menggunakan metode VCIRS, dapat ditarik kesimpulan bahwa sistem sudah bisa mendiagnosa penyakit tanaman anthurium dengan tingkat akurasi sebesar 92,3\%. Perhitungan metode VCIRS dalam mendeskripsikan knowledge base didalam sistem memberikan nilai penggunaan (usage rate) terhadap setiap rule dari setiap gejala $(V U R)$, rule penyakit $(R U R)$ dan node setiap rule (NUR). Pada metode inferensia untuk mencari nilai faktor keyakinan sistem terhadap suatu hasil diagnosa menggunakan metode Certainty Factor kombinasi antara keyakinan pakar dan user juga menggunakan nilai $R U R$ suatu penyakit tersebut.

Dari penelitian terhadap pendeteksian penyakit pada tanaman anthurium, perhitungan VCIRS nya belum lengkap karena masih terdapat satu tahapan lagi yaitu Relative Node Order. Untuk pengembangan aplikasi selanjutnya, pada fitur anggota sebaiknya dapat ditambahkan fitur untuk menambahkan gejala baru, ditampilkan kembali pertanyaan-pertanyaan ulang yang masih 
berhubungan dengan gejala baru dan perhitungan nilai $V U R, N U R, R U R$, dan presentase nilainya akan berubah secara dinamis.

\section{DAFTAR PUSTAKA}

[1] Argahartono Arie Raharjo, Hama \& Penyakit Tanaman Kenali \& Atasi. Jakarta: PT. Trubus Swadaya, 2017.

[2] Ade Candra Saputra, "Prototipe Sistem Pakar Dengan Metode Variable Centered Intelligent Rule System Untuk Mendiagnosa Penyakit Pada Anjing”, Jurnal Teknologi Informasi Jurnal Keilmuan Dan Aplikasi Bidang Teknik Informatika, vol. 2, No. 1, January 30, 2015. Available: https://e-journal.upr.ac.id/index.php/JTI/article/view/1514. [Accessed November 12, 2020]

[3] M. S. Josephine and V. Jeyabalaraja, "Expert System and Knowledge Management for Software Developer in Software Companies", Software Engineering and Technology, vol. 2, Mar., pp 243-247, 2012.

[4] I. Subakti, A Variable-Centered Intelligent Rule System, Edisi Jurusan T. Informatika - ITS, Surabaya, Institut Teknologi Sepuluh Nopember : Jurusan Teknik Informatika, 2006. [Ebook] Available: Subakti.com

[5] T. Sutojo, Kecerdasan Buatan. Yogyakarta: CV. Andi Offset, 2011.

[6] Lanny W. Lingga, Anthurium. Jakarta: PT. Gramedia Pustaka Utama, 2007.

[7] Adedeji Bodunde Badiru, Expert Systems Applications in Engineering and Manufacturing. New Jersey: Prentice Hall, 1992.

[8] Pipi Susanti, Nelly A. Hasibuan, dan Kurnia Ulfa, "Sistem Pakar Mendiagnosa Penyakit Vas, Kulitis Menggunakan Metode Variable Centered Intelligent Rule System (VCIRS)", Jurnal Konferensi Nasional Teknologi Informasi dan Komputer, vol 2, no. 1, 2018. 